\title{
Motoring Protection Model Implementations and Simulations for Generator Protection
}

\author{
Subrahmanya K. Devadig ${ }^{1}$, K. S. Aprameya ${ }^{2}$ \\ PG Scholar, Dept. of Studies in EEE, University B. D. T. College of Engineering, Davangere, India ${ }^{1}$ \\ Professor, Dept. of Studies in EEE, University B. D. T. College of Engineering, Davangere, India ${ }^{2}$
}

\begin{abstract}
One of the most delicate, costlier and important component of the power system is synchronous generator and a principal requisite for the power system stability and reliability. Since synchronous generators are rotating machines and always operate in parallel with a large power system network, so they might be prone to a number of internal faults or abnormal operating conditions such as loss of field, over excitation, overvoltage, current unbalance, loss of prime mover etc. Thus, the synchronous generators need to be protected very cautiously from such types of abnormal conditions. This paper has presented the modelling, simulation and analysis of a complete motoring protection system constructed on the software MATLAB/SIMULINK ${ }^{\circledR}$ for the motoring condition of a large synchronous turbo generator.
\end{abstract}

Keywords: Synchronous Generator, Motoring Protection, Reverse Power Relay, MATLAB/SIMULINK ${ }^{\circledR}$.

\section{INTRODUCTION}

Synchronous generators are the electrical machines that convert mechanical or thermal energy into useful electrical energy; they are also called as alternators. Generators are one of the most delicate and expensive components of the power system, as well as important components for stable and reliable operation of a power system. The synchronous generators are rotating electrical machines so they might be prone to internal faults or abnormal power system conditions, since synchronous generators are connected in parallel with a large power system network. Thus, the generators need to be protected very prudently in view of dependability, reliability and security aspects of the large power system network. A number of protection functions applied to the synchronous generator in case of abnormalities are motoring protection, current unbalance protection, loss of field protection, over excitation protection, overvoltage protection etc. [1-2]. In this paper the motoring protection i.e. reverse power protection of a large turbo generator is considered, when there is a failure of prime mover especially steam turbine.

In view of protection of the power system components, the synchronous generators constitute a different category of power system network component because even though the abnormalities that happen to generators are rare, but if they happen the result would be extremely destructive. Generation integrity of most utilities must be conserved by avoiding false tripping; removing a synchronous generator from the power system network during a serious abnormal condition is also a mandatory requirement. Moreover, protection must be provided to the synchronous generator for all the power system conditions that occur to the generator such as overvoltage, over excitation, loss of prime mover, negative sequence currents, etc.

\section{MOTORING CONDITION}

Electric power generally flows from the synchronous generator to the busbars. However, if the input to the prime mover (i.e. engine or turbine) of any generator fails due to an unavoidable circumstance, the busbars itself start supplying active power from the power system network to the generator and it runs as synchronous motor to drive the prime mover. In such a situation the active power flows in reverse direction and the generator currents are still balanced. This condition do pose no harm or a little harm to the generator; though the generator windings will be overheated but the reversal of power is very detrimental to the prime mover. In order to detect such operation and prevent damages to both the prime mover and the generator, a directional active power relay must be used. In this context the modelling, simulation and analysis of a complete motoring protection of a synchronous generator is presented.

Motoring condition might take place during synchronization process also, when the frequency of the synchronous generator to be synchronized with the large power network is a little lesser than that of the bus bar and the circuit breaker is closed. Hence the active power will flow from the bus bar to that synchronous generator. Therefore the frequency of the synchronous generator to be synchronized is kept a little higher than the frequency of the bus bar. This guarantees that the incoming synchronous generator takes on load immediately after the circuit breaker is closed [3].

A. Potential Damages

As a direct consequence of motoring condition during prime mover failure, the prime mover will get damaged if the reliable motoring protection is not in place. A number of incidents may occur under motoring condition of a generator. Firstly, the main stream pipe of the steam turbine may break. Secondly, there might be possibility of damages to one or more blades in the turbine and finally, the closing of the mainstream stop valves inadvertently. So, it is very essential to have a reliable motoring protection system [4]

Steam turbines need a constant stream flow in the turbine to eliminate the excess heat produced by turbulence or 
cavitations on or about the blades of the steam turbine [5]. Reversal of active power in a power system requires the So as a result of the reduction in the steam flow in the motoring protection. A reverse power relay along with a turbine during motoring condition, the cooling effect of timer can deliver sufficient motoring protection. A reverse the steam turbine blades also reduces and heat increases, power relay can be either a directional undercurrent relay which may cause distortion or softening of the steam or a directional over current relay. The current flowing to turbine blades. The Kaplan type and bulb type hydro turbines may also be damaged owing to the fact that the turbine blade surf on the water and set up an axial pressure on the bearing [6]. Gas turbines and diesel engines are less vulnerable to instant damage, however fire hazards or explosions may take place due to unburned fuel present in the diesel engine [3] and also diesel engines may be damaged because of inadequate lubrication. Therefore, reverse power protection is crucial for all power generating units except for the hydro units intended to run as synchronous condensers.

Especially in case of steam turbines, the reverse power condition causes many undesirable and unavoidable conditions. The rotation of the steam turbine rotor and blades in a steam atmosphere causes wind age losses. Since wind age loss is a derivative of the diameter of rotor disc and blade length, the wind age loss will typically be maximum in the steam turbine exhaust end. Wind age loss energy is dissipated as heat.

The flow of steam through a steam turbine has two main advantages, to provide energy to cause rotation of the rotor and to take away the heat of the parts of the steam turbine. During motoring condition since the steam is not flowing enough through the steam turbine, the heat of the wind age losses is not taken away; thereby causing the steam turbine to overheat. The high pressure steam turbines usually have very high wind age losses [7].

\section{III.REVERSE POWER RELAY (ANSI/IEEE CODE 32)}

Motoring is defined as the flow of real power into the synchronous generator acting as a synchronous motor which happens if the generator loses its prime mover (i.e. engine or turbine) input (loss of steam flow or fuel). Since the current is still flowing in the synchronous generator field winding, the generator will continue to be in synchronism with the power system network and run as a synchronous motor. A reverse power relay must be employed to monitor the synchronous generator during such condition. The reverse power relay is designated as 32 according to ANSI/IEEE device number system. The sensitivity and setting of a reverse power relay is completely dependent on the type of prime mover (i.e. engine or turbine) involved. The power needed to motor is a derivative of the load and mechanical losses of the idling prime mover and synchronous generator [7].

Many a times the motoring condition may infer that the turbine is in a hazardous condition. The principal task of the motoring protection system is to protect the prime mover but not to protect the synchronous generator. The motoring protection system is normally energized by ac current and voltage supplied by the instrument transformers and it trips the synchronous generator circuit breaker. Hence synchronous generator protection incorporates the motoring protection. diver system network from the synchronous generator is sensed by the directional undercurrent relay whereas the current flowing from to the synchronous generator the power system network is sensed by the directional over current relay. A few sensitive current relays existing in the power system can bear the normal load current uninterruptedly but the relay must also briefly bear the fault current that might flow through it during an abnormal condition. The settings of timer should be in the range of a few seconds to some minutes [4].

The main intention of the reverse power relay is to prevent damage to the prime mover (i.e. engine or turbine) during motoring condition. If the driving torque becomes less than the total losses in both the generator and the prime mover are added together, the synchronous generator begins to work as a synchronous compensator, consuming the required amount of active power from the power system network.

In gas turbines, the large compressor requires a considerable amount of power from the power system network, up to $50 \%$ of the nameplate rating of the synchronous generator, so in this particular case the sensitivity of the reverse power relay is not a major problem. A diesel engine with no cylinders firing requires up to $25 \%$ of nameplate rating of the synchronous generator, so there is also not any problem of sensitivity for the reverse power relay. However, the diesel engine manufacturer should be consulted for accurate value of reverse power rating of a particular diesel engine at the time of commissioning the plant. As far as hydro-turbines are concerned, when the blades are under the tail-race water level, the reverse power required is high. However, when those are above the tail-race level, low reverse power is required i.e. between $0.2 \%$ and $2.0 \%$ of the nameplate rating of the synchronous generator and a sensitive reverse power relay may be necessary for the latter case. The Steam turbines operating under full vacuum and zero steam input consumes about $0.5 \%$ to $3 \%$ of nameplate rating of the synchronous generator to motor and to detect such condition a reverse power relay with high sensitivity is necessary [7]. These conditions differ from turbine to turbine, So It is very necessary to obtain information regarding the reverse power rating from the engine or turbine manufacturer and to measure the reverse power at the time of commissioning of the plant.

Table 1 Typical Motoring Power and Potential Damages [8]

\begin{tabular}{|c|c|c|}
\hline $\begin{array}{c}\text { Type of } \\
\text { Generator }\end{array}$ & $\begin{array}{c}\text { Motoring } \\
\text { Power(kW) }\end{array}$ & Potential Damages \\
\hline Steam Turbine & $0.5 \%-3 \%$ & Overheating/Explosion \\
\hline Diesel Engine & $5 \%-25 \%$ & Fire/Risk of explosion \\
\hline Hydro Turbine & $0.2-2 \%$ & Blade cavitation \\
\hline Gas Turbine & $>50 \%$ & Gear box damage \\
\hline
\end{tabular}


The Table 1 provides a brief description about the typical It is a directional relay with leading maximum torque reverse motoring power requirements and the potential damages for different generator prime mover (i.e. turbine or engine) types. For generator motoring protection, the reverse power relay is normally set between $20 \%$ and $50 \%$ of the reverse power (i. e. motoring power) needed to drive prime mover. The motoring power is the minimum power needed for the synchronous generator to run the prime mover at the rated rpm. The reverse power rating is usually obtained from the turbine manufacturer at the time of installation of the plant or station. In order to protect the synchronous generator during motoring condition, the reverse power setting of a reverse power relay is selected based on the type as well as the rating of the synchronous generator and is defined by the equation [9],

Reverse Power Setting =

Rated Generator Capacity (MVA) × Rated Motoring Power (\%) CTratio x VTratio

Digital technology gives many additional features today, which could not be accomplished in a single package with earlier available technology. These specific features include: metering of voltages, currents, power, and other measurements; event recording and oscillography; remote setting and monitoring through communications; user configurability of tripping arrangements; decreased panel space and wiring; low load on the voltage and current transformers and uninterrupted self-checking. Digital relays provide benefit of small in size, fast and reliable in their operation in the event of power system abnormalities and also they give advantages in sensitivity and a broad spectrum of controllability.

Simulation tools provide opportunity to acquaint with realtime operation and also to study and analyse the normal, transient and dynamic conditions of the power system. The software MATLAB/SIMULINK ${ }^{\circledR}$ offers the Sim Power Systems package for power system engineers. In this paper, the modelling, simulation and analysis of motoring protection of a large turbogenerator is constructed on the MATLAB/SIMULINK ${ }^{\circledR}$ platform and modelling of several basic elements and logic schemes are implemented and simulation results are discussed.

\section{A. Principle and Operation of Reverse Power Relay}

Even when the synchronous generator is working as a synchronous motor in the event of the prime mover failure, the generator stator currents are still balanced in motoring condition and hence a single phase relay protection scheme is sufficient.

A reverse power relay is a $1 \phi$ directional relay used to protect synchronous generators from motoring during failure of prime mover (i.e. engine or turbine). It detects the flow of power from the power system network into the generator. If this power flow prolongs for a pre-set time, the reverse power relay takes appropriate action and trips the generator breaker [10]. Reversal of power is detected by a reverse power relay. These relays are very sensitive to reactive power rather than real power that flow in the power system network.

angle. Under abnormal condition i.e. prime mover (i.e. engine or turbine) failure; the current reversal takes place and the direction of power changes from the bus bar into the synchronous generator, this condition is sensed by the reverse power relay and it operates to trip the synchronous generator. The real power drawn from the power system is relatively small as compared to the rating of the synchronous generator. On the other hand, stator current of the synchronous generator undergoes $180^{\circ}$ phase shift which is shown in figure 1 referred to as Maximum Torque Angle (MTA). Thus, if a directional relay with MTA of $180^{\circ}$ is used then it could sense turbine failure as the current would reverse. But the magnitude of the reversed current phasor is very small as compared to the forward current since the real power drawn by the synchronous generator is only just required to meet the losses and drive the prime mover. Therefore, the directional relay employed to detect and monitor the reverse power flow during motoring condition must be very sensitive as compared to overcurrent directional relays.

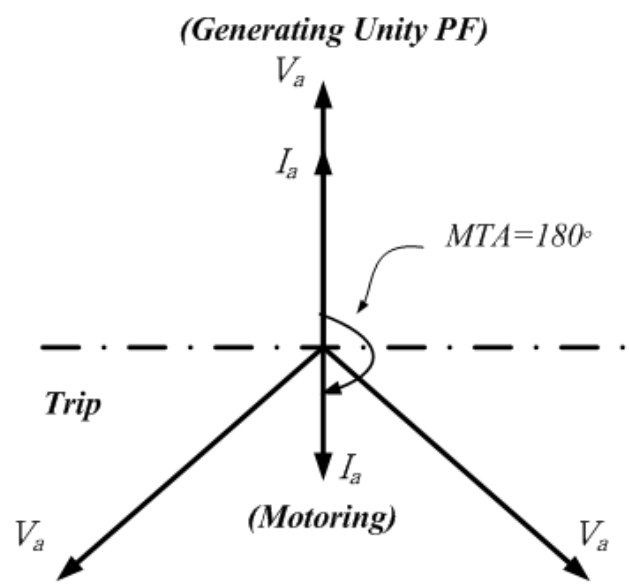

Fig.1. Phasor diagram of current and voltages during motoring condition

Where a sensitivity of better than $3 \%$ accuracy is needed in the protection of power system applications, a metering class instrument transformer i.e. current transformer ought to be used in order to get rid of incorrect protection performance because of current transformer phase angle errors as and when the synchronous generator delivers a considerable level of reactive power almost at zero power factor or very close to zero power factor. The motoring protection must be employed with a definite time delay upon operation to avoid abrupt operation with dynamic and transient power oscillations that might take place following synchronization or in the event that disturbances happen in the transmission system [11].

Reverse power relay should be as much as sensitive enough to sense the power lower than the amount of power needed to motor the synchronous generator. As far as steam and hydro turbines are concerned the sensitivity of reverse power relay is very much essential than reciprocating engines and gas turbines are concerned. 
Single-phase active power is expressed by $\mathrm{P}=\mathrm{V}$ I $\cos \phi$, integral output starts to fall and reaches the set threshold where $\mathrm{V}$ and $\mathrm{I}$ are the rms values of the voltage and the ' $\mathrm{L}$ ' during reverse power flow conditions. Here the value current of each phase respectively, and ' $\phi$ ' is the angle of ' $L$ ' is kept at 0.03 . The ' $L$ ' value to be selected is between the rms voltage and the rms current referred as power factor angle. From the above expression it can be concluded that the measured active power will be negative only if the ' $\cos \phi$ ' becomes negative. The ' $\cos \phi$ ' has positive values in the range of $-90^{\circ}<\phi<90^{\circ}$, that correspond to the range of positive values of real power and in the range of $+90^{\circ}<\phi<270^{\circ}$, the values of active power going to be negative. Therefore, when the difference of angle between the rms voltage and the rms current is more than $90^{\circ}$; the reverse flow of the active power can be found out [8].

Let the angle between the current I and voltage $\mathrm{V}$ on any phase of the power system is ' $\phi$ '; then under normal direction of power flow, the range of angle will be $-90^{\circ}$ $<\phi<90^{\circ}$ and it will be between $+90^{\circ}$ and $270^{\circ}$ during reversed power flow condition. The observation is that the interval of overlap between voltage $\mathrm{V}$ and current $\mathrm{I}$ is much longer than their non-overlapping interval during normal conditions. However, the overlapping interval between them decreases to a low level i.e. much shorter than their non-overlapping interval in case of reverse power flow i.e. during abnormal condition. The interval difference of overlapping both under normal and reversed power flow conditions (i.e. motoring condition) will be used to model the directional element of the reverse power relay.

\section{IV.MODELLING OF MOTORING PROTECTION}

The complete motoring protection model constructed on MATLAB/SIMULINK ${ }^{\circledR}$ includes modelling of reverse power relay, generator breaker trip control logic and field breaker trip logic subsystems. The modelling and implementation of the individual components is described in the following sections.

\section{A. Modelling of Reverse Power Relay}

In this particular model, the relay to be implemented is split up into directional element, time delay element and hold element as three main parts and the following subsection describes the modelling techniques of each individual element or block, also the models implemented on MATLAB/SIMULINK are shown.

1) Directional Element:

The main reason for introducing and modelling of this particular part is to sense the power flow direction during motoring condition of the synchronous generator in the power system. In this element, low level current and voltage signals from current and potential transformers are converted into a square wave with ' +1 ' or ' -1 ' for positive and negative values of signals respectively. These converted square waves are then multiplied to give either ' +1 ' or ' -1 ' for the overlapping and the non-overlapping interval respectively. Then the resulted output is integrated from ' 0 ' to '- $\mathrm{L}$ ' by holding the upper limit at ' 0 ' so as to maintain the integrator output to less than ' 0 ' during normal load flow circumstances. On the other hand, the dependent upon the amount of reverse power required as it depends on the rating of synchronous generator and the SIMULINK modelled directional element is shown in figure 2 .

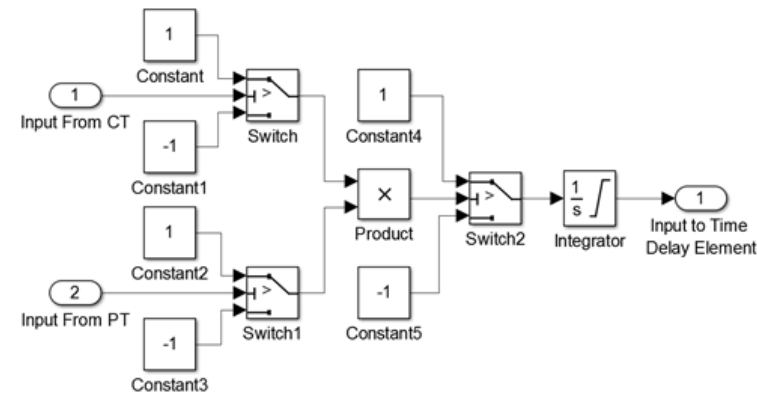

Fig.2. Modeled directional element on SIMULINK.

\section{2) Time Delay Element:}

Wherever reverse power relays are used, especially for motoring protection in this case; it is always applied with accurate time delay. The time delay is selected such that it must be corresponding to the permissible turbine motoring time and must be less than the highest permissible motoring time stated by the prime mover (i.e. engine or turbine) manufacturer. The delay time varies inversely as the capacity of the generator varies; that is as the generator capacity increases, the delay time to be set decreases accordingly. A time delay of up to 60 seconds may be used to avoid operation of reverse relay during power swings caused by power system disturbances or when synchronizing the synchronous generator to the power system network. For steam turbines a typical time delay of 30 seconds is applied [7].

The main intention of modeling this particular element is to incorporate sufficient time delay so as to prevent the reverse power relay from sending nuisance tripping signals to the circuit breaker during transient or momentary fault situations. In present case the time delay for main reverse power relay is set to 9 seconds and 10 seconds for backup reverse power relay in order that such dynamic reactions are by-passed. The following figure 3 shows the SIMULINK model of time delay element. While implementing the logic for the time delay element, the output of the directional element is given to the input of the time delay element.

Input of time delay element is given the output of the directional element, the output of directional element may be either 0 or 1 , in case of normal and abnormal power flow (i.e. motoring condition) conditions respectively. Subsequently this output is integrated and the resultant integral value is compared with the preset threshold value ' $T$ '. The value of ' $T$ ' is set to the amount of delay time required for the motoring protection.

During normal operation, as the input available at the integral block is ' 0 '; so the integral output value will also be ' 0 ' i.e. less than the value of ' $T$ '. Hence the time delay element output will be ' 1 ', indicating normal power flow condition. Conversely under abnormal power flow 
condition, the input available at the integral operator will be ' 1 ' and exactly ' $T$ ' seconds after output value of the integrator operator will exceed the set threshold value ' $\mathrm{T}$ '; as a result the output value of the time delay element will be ' 0 ', implying a fault condition i.e. reverse power flow condition. In the event that a momentary fault or transient situation which happens in the power system accounts only for a time duration of less than ' $\mathrm{T}$ ' seconds and as soon as the fault or transient vanishes, the relational operator will immediately reset the integral operator to ' 0 ', value.

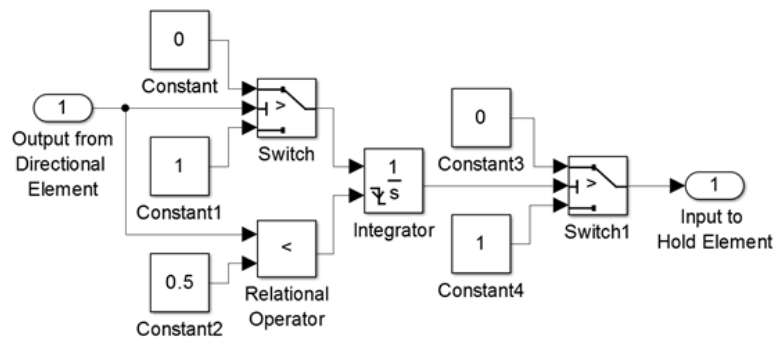

Fig.3. The SIMULINK ${ }^{\circledR}$ model of time delay element.

\section{3) Hold Element:}

The principal idea and aim of modeling and implementing this particular element is to keep the reverse power relay remain in steady condition after it has tripped following an abnormal condition in the power system network. This specific behavior of the relay is basically due to the fact that once the circuit breaker has operated; the fault condition will continue to exist; implying abnormal load flow condition thereby making the reverse power relay to close the circuit breaker again by applying close (i.e.' 1 ') signal to it. Therefore, such situation will be prevented by implementing this element in the model of the reverse power relay. The hold element modeled on SIMULINK is shown in figure 4. While implementing the logic for hold element the output of the delay element will be input of the hold element.

The time delay element output (i.e. ' 0 ') is applied to the input of the hold element, subsequently it is inverted and integrated. As the integral output value crosses ' 0 ', the hold element output will change to value ' 0 ' from value ' 1 ' and once the output of the integral operator surpasses its threshold limit ' 0 ' the integral operator cannot reset thereafter and hence it will not return back again to that value. Thus the hold element output value will remain unchanged, that is ' 0 ' value at all times. A switch is introduced in between the input of hold element and the output of time delay element to get rid of unwanted tripping of the reverse power relay during initial period of transients in the power system network.

After the modeling of these three basic elements, the complete reverse power relay is modeled and implemented on SIMULINK using these individual element or parts combined together by giving the output of directional element to the input of time delay element, then the output of time delay element is given to the input of the hold element and finally the output of the whole model, i.e. the modeled reverse power relay is given to the three phase circuit breaker.

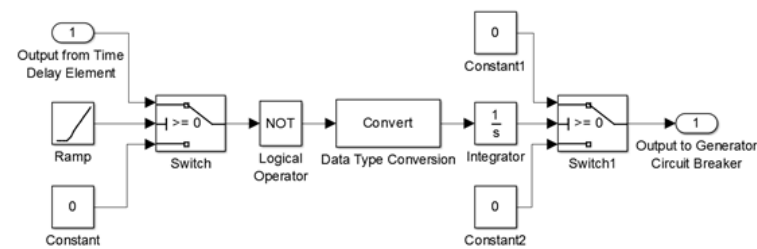

Fig.4. Hold element modeled on SIMULINK.

\section{B. Modelling of the Generator Trip Control Logic}

This is the essential component of the whole motoring protection model. In order to provide maximum protection security to the synchronous generator, the possibility of failure of the reverse power relay is considered here in this specific model. The complete generator trip control logic subsystem implemented on SIMULINK is shown in figure 5. This model consists of a circuit breaker trip logic subsystem and two reverse power relays out of which one reverse power relay i.e. backup relay is for synchronous generator protection in case of malfunction or failure of main relay and hence, a circuit breaker trip control logic is implemented to prevent such condition. The backup relay set at the same sensitivity with a little longer time delay than that of the main relay is used in this generator breaker control trip control logic. The backup relay protection is always applied with an appropriate time delay. In this particular case, the time delays of main relay and backup relay are set at 9 seconds and 10 seconds respectively. The circuit breaker trip control logic subsystem implemented on SIMULINK is shown in the figure 6.

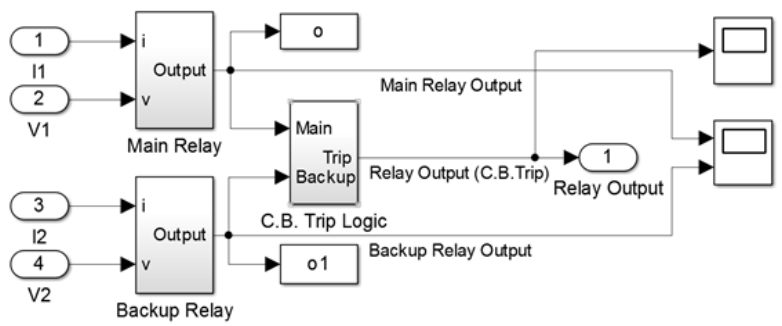

Fig.5. Generator trip control logic subsystem on SIMULINK.

The synchronous generator stator currents are still balanced even under reverse power flow condition; therefore a single phase relay scheme is enough, if the sensitivity is high and also in case of large synchronous steam turbo generators, a backup relay may be connected to a different phase so as to provide maximum protection [6]. So, in this control logic both the reverse power relays (i.e. main and backup) are connected to the different phases of the power system to facilitate backup protection. In the generator trip control logic subsystem, the outputs from both the reverse power relays (i.e. main and backup relay) are applied to the circuit breaker trip logic subsystem, where a relational operator compares both the values with each other, so as to confirm that whether the output values of both the relays are same (i.e. either only ' 0 's or ' 1 's) or not; value ' 1 ' during normal and ' 0 ' during abnormal power flow conditions. When the output values of both the relays are same, the output of the circuit breaker trip logic subsystem will be the output of the main 
relay. However, in case of failure of the main relay, the output value of the main relay is still ' 1 ' even during the abnormal power flow condition; which is not same as the desired output value (i.e. '0') of the backup relay and hence the output of the circuit breaker trip logic subsystem will be the output of the backup relay, but not the output of the main relay.

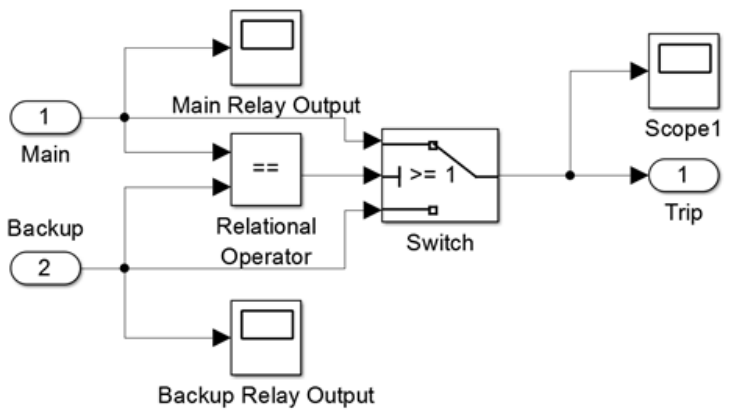

Fig.6.Circuit breaker trip control logic subsystem on SIMULINK.

\section{Modelling of the Field Breaker Trip Control Logic}

The main purpose of introducing and implementing this model is to trip the field breaker of the synchronous generator immediately after generator breaker has tripped. The generator field breaker trip control logic is controlled by both of the reverse power relay outputs i.e. either output of the main relay or output of the backup relay. In this case, the trip signal either from the output of the main reverse power relay or from the output of the backup reverse power relay is delayed for a second in the generator field breaker trip control logic subsystem and hence, the generator field breaker will trip after a second later than the time delay set for the main and backup relays. However, both the generator breaker and the field breaker can be tripped simultaneously.

Under the normal operating condition of the main relay since the field breaker trip control logic is now supervised by the main relay; hence, the field breaker will trip after a time delay of 10 seconds, because the main relay is set at a time delay of 9 seconds. Under the abnormal operating condition (i.e. failure) of the main relay since the field breaker trip control logic is now supervised by the backup relay; hence, the field breaker will trip after a time delay of 11 seconds, because the backup relay is set at a time delay of 10 seconds. However any value of time delay for the relays can be set based on the desired reverse power required for the synchronous generator for which motoring protection is applied. The SIMULINK modeled field breaker trip control logic is shown in figure 7 .

The complete motoring protection SIMULINK model comprised of the generator trip control logic subsystem and the field breaker trip control logic is employed in the power system network is shown in figure 8 . The power system considered here consists of a three phase transformer, three phase loads, a source and a synchronous turbogenerator. The parameters of these components are given in appendix. The testing and simulations of the motoring protection model is carried out and simulation results are studied for different and changing mechanical inputs to the synchronous turbogenerator on MATLAB/SIMULINK ${ }^{\circledR}$

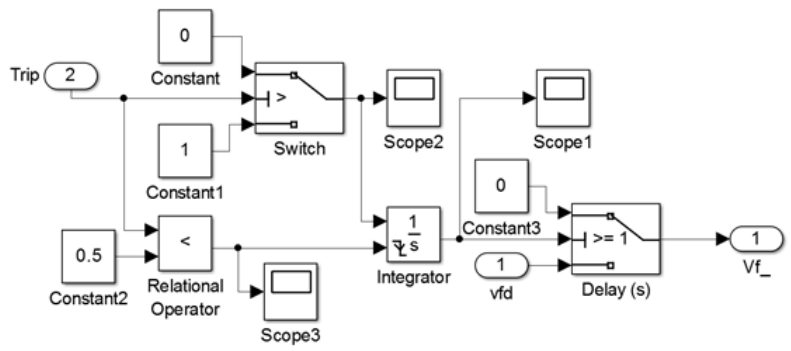

Fig.7.The SIMULINK modeled field breaker trip control logic subsystem

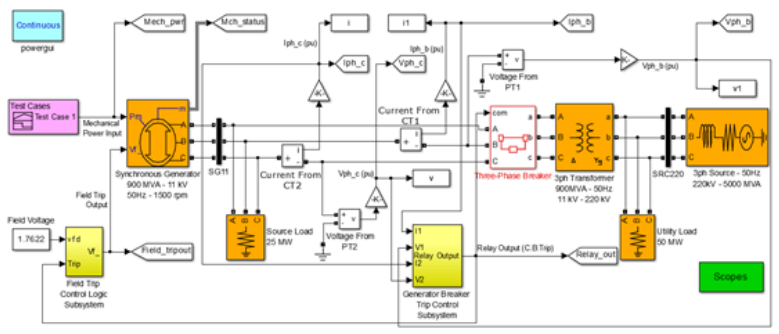

Fig.8.The complete motoring protection SIMULINK model.

\section{SIMULATION RESULTS}

In order to simulate and test the motoring protection model under both normal and abnormal power flow (i.e. reverse power flow) conditions, a large synchronous steam turbo generator having rating of $900 \mathrm{MVA}, 11 \mathrm{kV}, 50 \mathrm{~Hz}$ is used and it is connected to $11 \mathrm{kV}$ power system network through a three phase step up transformer with rating $11 \mathrm{kV} / 220 \mathrm{kV}$, $50 \mathrm{~Hz}$ is illustrated in figure 8 . The details and parameters of all the components are provided in the appendix given at the end.

The designed SIMULINK motoring protection model is simulated for diverse test conditions for changing inputs of mechanical power to the generator; as well as simulated for failure of reverse power relay i.e. main relay. Discussions on a specific test case and simulation results are illustrated in the following section.

\section{A. Test Case}

In this specific test case, the mechanical input power to the synchronous turbo generator varies a number of times from 0 seconds to 100 seconds and this particular situation is tested overall for 160 seconds. In this particular test case the two consequences, the healthy operation of the main reverse power relay and the possibility of failure of the main reverse power relay are considered.

1) Normal Operation of Main Reverse Power Relay:

In this case, the normal working operation of the main reverse power relay is considered. It can be seen from figures $9,10,11,12$ and 13 that the generator trip control logic subsystem functions accurately and securely for all mechanical power input variations and isolates the synchronous turbo generator from the power system 
network by tripping the generator circuit breaker at 109 seconds, i.e. 9 seconds after the moment at which the mechanical power input to the turbo generator fails and hence the generator field breaker also trips 1 second after the generator breaker has tripped i. e. at 110 seconds.

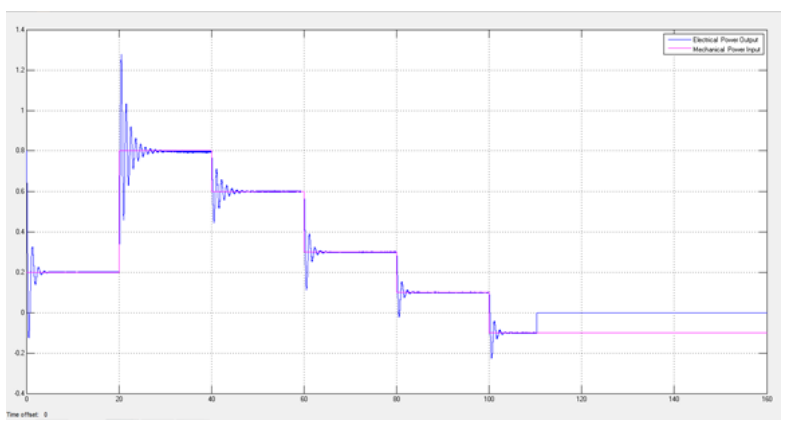

Fig. 9. Mechanical input (pu) and electrical output active power $(\mathrm{pu})$

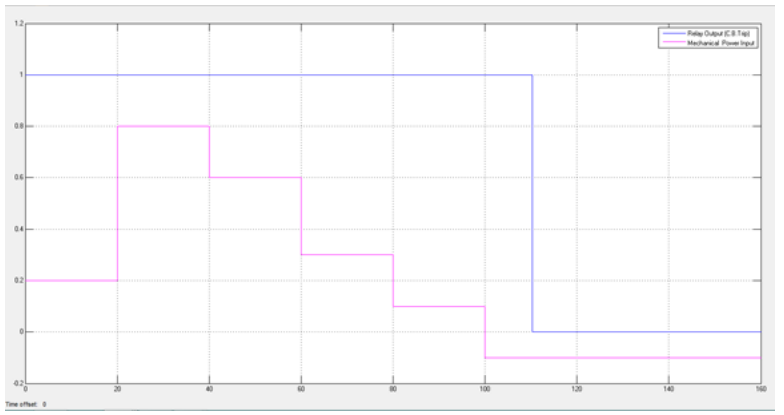

Fig. 10. Output of the generator trip control logic subsystem (Relay output - C.B. trip)

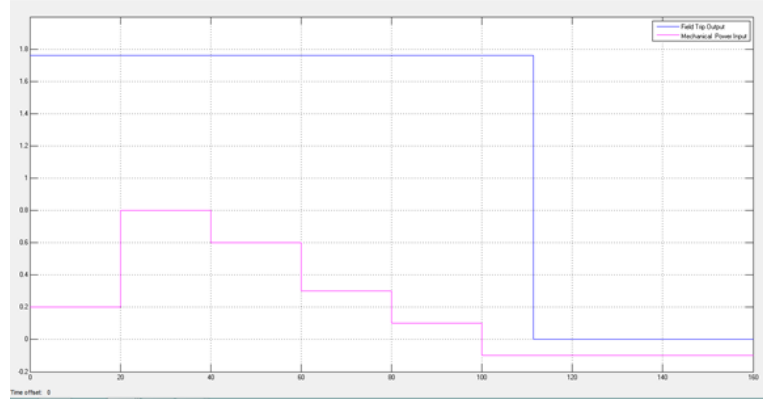

Fig. 11. Output of field trip control logic subsystem (Field trip output)

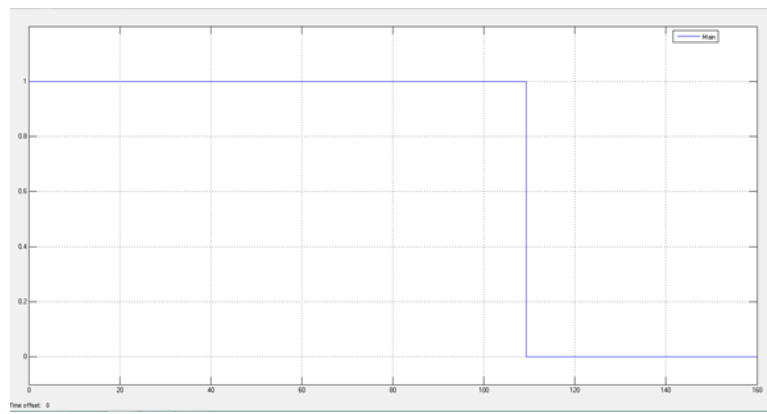

Fig.12. Output of main reverse power relay

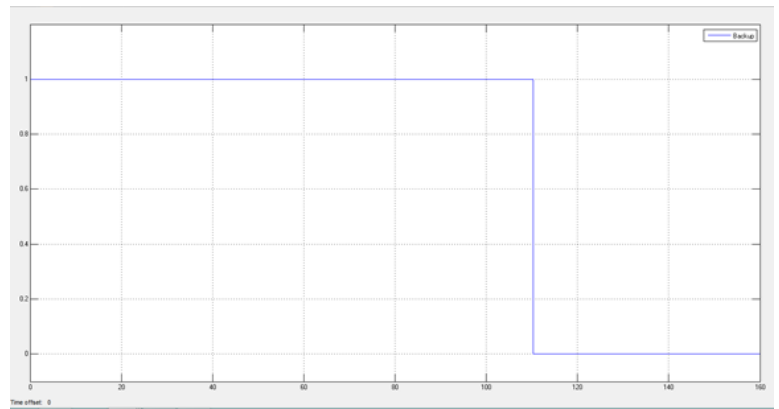

Fig.13. Output of backup reverse power relay

2) Failure of Main Reverse Power Relay:

In this particular consequence, malfunctioning of the main reverse power relay is considered. For that purpose, here in the present case the main reverse power relay is intentionally made to malfunction or work as abnormal in order to simulate and check the designed motoring protection model by making the output of the main reverse power relay same as it was in the normal condition (i.e. ' 1 ') even during motoring condition and hence the backup reverse power relay operates immediately after confirming that the main reverse power relay has not operated at predetermined time delay. It can be observed from the figures $14,15,16,17$ and 18 that the generator trip control logic subsystem works appropriately and safely for all mechanical power input deviations and cut off the synchronous turbogenerator from the power system by tripping the generator breaker at 110 seconds, i.e. 10 seconds after the instant at which the mechanical input to the synchronous turbogenerator fails and hence the generator field breaker trips 1 second after the generator breaker has tripped i. e. at 111 seconds.

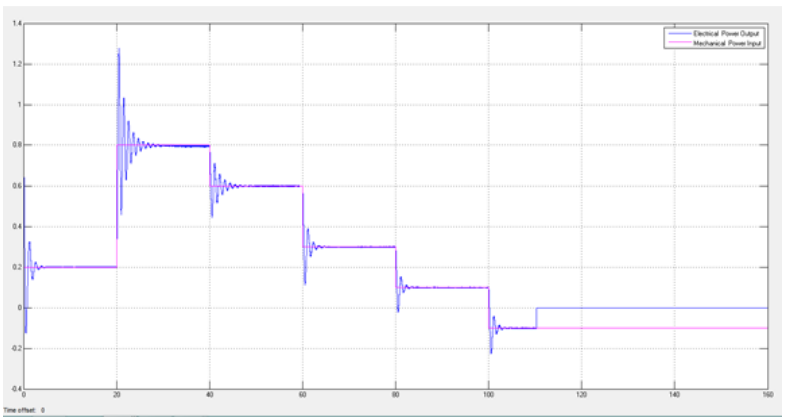

Fig. 14. Mechanical input (pu) and electrical output active power (pu)

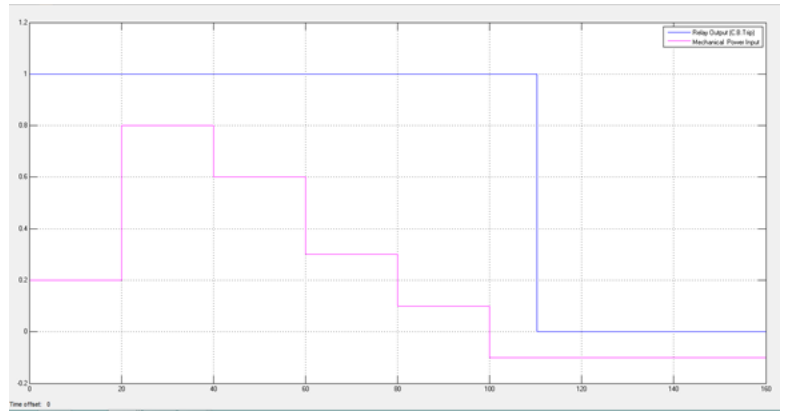

Fig.15. Output of the generator trip control logic subsystem (Relay output - C.B. trip) 


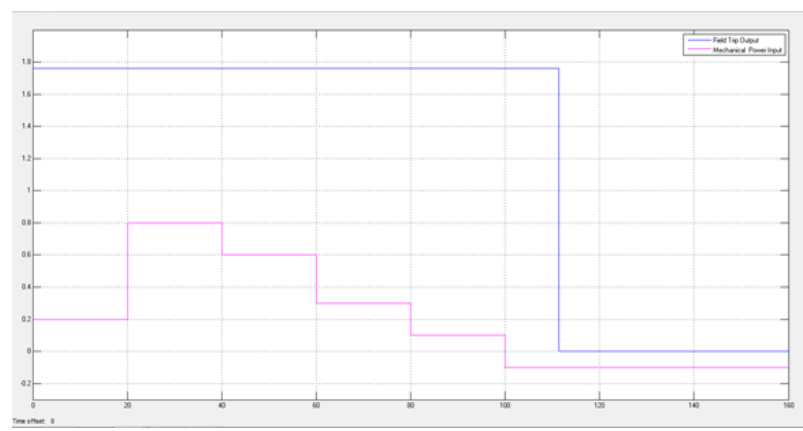

Fig. 16. Output of field trip control logic subsystem (Field trip output)

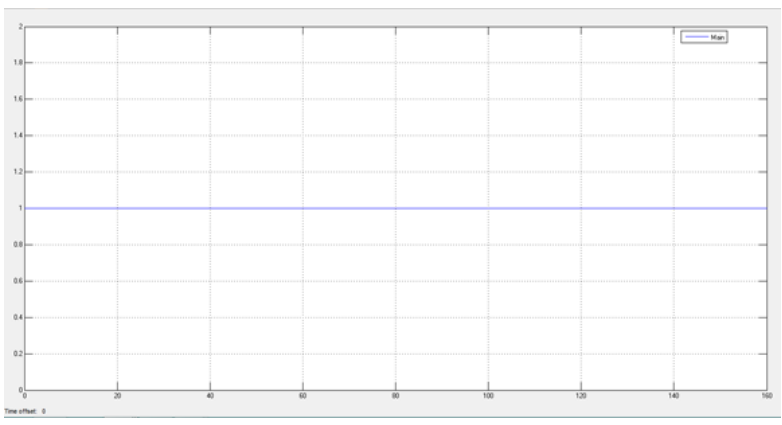

Fig. 17. Output of the failed main reverse power relay

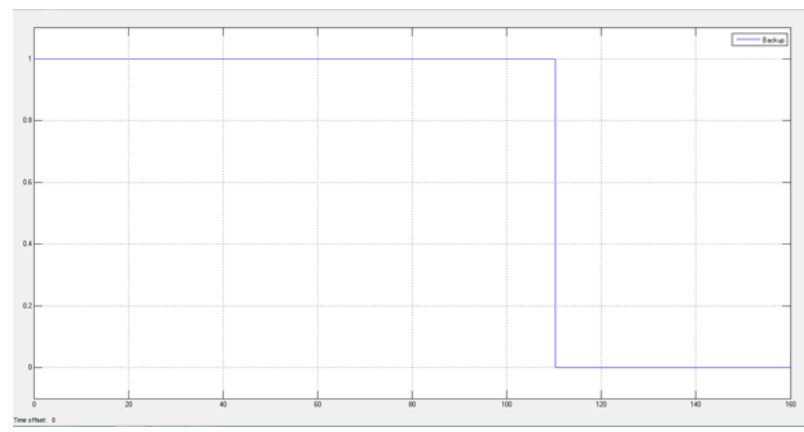

Fig.18. Output of the backup reverse power relay during main relay failure.

\section{VI.CONCLUSION}

This paper has presented the modelling, simulation and analysis of a complete motoring protection system implemented using the package SimPowerSystems of the software MATLAB/SIMULINK ${ }^{\circledR}$ for the motoring condition of a large synchronous steam turbogenerator. The designed motoring protection model has been simulated for a number of test cases with varying mechanical power inputs to the generator and the results obtained are thoroughly studied for the analysis of generator protection system.

As far as other power system tools available till now are concerned, the MATLAB/SIMULINK ${ }^{\circledR}$ provides the benefit of flexibility in modification of both design and testing parameters of the motoring protection system model. The models designed and implemented using SIMULINK $^{\circledR}$ would definitely facilitate studying and analysing the power system more accurately and efficiently both during normal and abnormal conditions.

\section{REFERENCES}

[1] "Generators protection: Ekip G trip unit for SACE Emax 2", (C) ABB 2011.

[2] "Power Generation Handbook: Chapter 31-Synchronous Generators", www.digitalengineeringlibrary.com, (C) The McGrawHill Companies, 2004.

[3] Muhammad Mohsin Aman et al., "Modeling and Simulation of Reverse Power Relay for Generator Protection”. In 2012 IEEE International Power Engineering and Optimization Conference (PEOCO2012), Melaka, Malaysia: 6-7 June 2012, 2012.

[4] "Distribution Automation Handbook - Section 8.12 Generator Protection", (C) ABB Oy 2011

[5] "Instruction Manual for Directional Power Relays BE1-32 and BE1-32O/U”, Basler Electric Publication Number: 9171100 990, (c) Basler Electric 2007.

[6] ABB, "Reverse Power Relay and Protection Assemblies", Available on: http://www05.abb.com

[7] "IEEE Guide for AC Generator Protection", IEEE Power Engineering Society @ IEEE 2007.

[8] "IEEE Tutorial on the Protection of Synchronous Generators", Special Publication of the IEEE Power System Relaying Committee, John Wiley \& Sons, Inc., Publication,@ IEEE 2011.

[9] C. Buque, S. Chowdhury, and S.P. Chowdhury, "Modelling and Simulation of Reverse Power Relay for Loss of Mains Protection of Distributed Generation in Microgrids", (C) IEEE 2013.

[10] ABB, "SRW Reverse Power Relay", Available on: http://www05.abb.com.

[11] "Chapter 17: Generator and Generator-Transformer Protection Network Protection \& Automation Guide", pp. 293, ALSTOM T\&D Energy Automation \& Information (2002).

[12] Muhammad Mohsin Aman, Ghauth Bin Jasmon, Hazlie Bin Mokhlis, Qadeer Ahmed Khan, Ab. Halim Bin Abu Bakar, and Mazaher Karimi, "Modeling and Simulation of Digital Frequency Relay for Generator Protection". In 2012 IEEE International Conference on Power and Energy (PECon), Kota Kinabalu Sabah, Malaysia: 2-5 December, 2102.

[13] Kalpesh J. Chudasama, Hardik Shah, and Brijesh Patel, "Practical Simulation of Power System Protection Laboratory Experiments Using Construction-wise Classified Relays", MIT International Journal of Electrical and Instrumentation Engineering, Vol. 2, No. 1, Jan. 2012, pp. (14-18), ISSN 2230-7656, ( MIT Publications.

[14] Ramón Sandoval, Armando Guzmán and Héctor J. Altuve, "Dynamic Simulations Help Improve Generator Protection", Comisión Federal de Electricidad, Schweitzer Engineering Laboratories Inc., ( ) SEL 2006.

[15] Rashesh P. Mehta and Bhuvanesh Oza, "Laboratory Simulation of Generator Protection", Fifteenth National Power Systems Conference (NPSC), IIT Bombay, December 2008.

[16] Muhammad Mohsin Aman, Muhammad Qadeer A. Khan, and Saad A. Qazi, "Digital Directional and Non-Directional Over Current Relays: Modelling and Performance Analysis", NED University Journal of Research, vol. 8, 2011.

[17] Geoff Klempner and Isidor Kerszenbaum, "Handbook of Large Turbo-Generator Operations and Maintenance" (C) IEEE 2008.

[18] Sezai Taşkin, "Power Plants Monitoring for Reverse Power Plow Evaluation", Journal of Electrical \& Electronics Engineering, Istanbul University, Vol. 10, No. 1, 2010.

[19] Mital Kanabar, Zhiying Zhang, and Vijaysarathi Muthukrishnan, GE Digital Energy, Wenping Wang, Ontario Power Generation, Mike Southwood and Jovan Momic, Eastern Power, Manish Das, GE Energy, "Comprehensive Testing of Generator Protection Systems".

[20] Pathinkar, Y.G. and Bhide, S.R., "Fundamentals of Power System Protection”, PHI Learning Pvt. Limited (2008).

[21] Arun G. Phadke and James S. Thorp "Computer relaying for power systems", ISBN: 0-471-92063-0, ( John Wiley \& Sons, Inc. New York, NY, USA, 1988.

[22] Gabriel Benmouyal, "Chapter 2: The Protection of Synchronous Generators", Schweitzer Engineering Laboratories, Ltd. (C) Taylor \& Francis Group, LLC, 2006

[23] J. Lewis Blackburn and Thomas J. Domin, "Protective Relaying Principles and Applications", Third Edition, (C) Taylor \& Francis Group, LLC, 2006.

[24] P. Kundur, "Power System Stability and Control" (C) McGraw-Hill, Inc., 1994. 
INTERNATIONAL JOURNAL OF INNOVATIVE RESEARCH IN ELECTRICAL, ELECTRONICS, INSTRUMENTATION AND CONTROL ENGINEERING Vol. 3, Issue 8, August 2015

\section{APPENDIX}

The details of various components used in the simulation are given below.

1) Synchronous Turbo generator:

Apparent Power, $\mathrm{S}=900 \mathrm{MVA}$

Line-to-Line Voltage (RMS), $\mathrm{V}_{\mathrm{L}-\mathrm{L}}=11 \mathrm{kV}$

Frequency, $\mathrm{f}=50 \mathrm{~Hz}$

Number of Poles, $\mathrm{P}=4$ (Round rotor)

Synchronous Speed, Ns = 1500 RPM

2) Three Phase Step-up Transformer:

Apparent Power, $\mathrm{S}=900 \mathrm{MVA}$

Primary Line-to-Line Voltage (RMS), $\mathrm{V}_{\mathrm{P}(\mathrm{L}-\mathrm{L})}=11 \mathrm{kV}$

Primary Line-to-Line Voltage $(\mathrm{RMS}), \mathrm{V}_{\mathrm{s}(\mathrm{L}-\mathrm{L})}=220 \mathrm{kV}$

Frequency, $\mathrm{f}=50 \mathrm{~Hz}$

3) Three Phase Source:

Apparent Power, $\mathrm{S}=5000 \mathrm{MVA}$

Line-to-Line Voltage (RMS), $\mathrm{V}_{\mathrm{L}-\mathrm{L}}=220 \mathrm{kV}$

Frequency, $\mathrm{f}=50 \mathrm{~Hz}$

4) Three Phase RLC (Resistive) Load 1: (Local Load)

Line-to-Line Voltage (RMS), $\mathrm{V}_{\mathrm{L}-\mathrm{L}}=11 \mathrm{kV}$

Active Power, $\mathrm{P}=25 \mathrm{MW}$

Frequency, $\mathrm{f}=50 \mathrm{~Hz}$

5) Three Phase RLC (Resistive) Load 2: (Utility Load)

Line-to-Line Voltage (RMS), $\mathrm{V}_{\mathrm{L}-\mathrm{L}}=220 \mathrm{kV}$

Active Power, $\mathrm{P}=50 \mathrm{MW}$

Frequency, $\mathrm{f}=50 \mathrm{~Hz}$ 